http://jmscr.igmpublication.org/home/ ISSN (e)-2347-176x ISSN (p) 2455-0450 crossref DOI: https://dx.doi.org/10.18535/jmscr/v9i1.03

\title{
Case Report \\ Histological Diagnosis of Vanishing Testis Syndrome (VTS) in an Atrophic Testis: A Case Report
}

\author{
Authors \\ Dr Rinku Susan Kurian ${ }^{1}$, Dr Sankar $S^{2}$, Dr Saji Varghese ${ }^{3}$ \\ ${ }^{1}$ Junior Resident, Dept. of Pathology, Govt. Medical College, Kottayam \\ ${ }^{2}$ Professor and Head of the Department, Pathology, Govt. Medical College, Kottayam \\ ${ }^{3}$ Assistant Professor, Dept. of Pathology, Govt. Medical College, Kottayam
}

\begin{abstract}
Vanishing testis syndrome(VTS)/Testicular regression syndrome(TRS) is a condition which is considered to be due to the subsequent atrophy and disappearance in fetal life of an initially normal testis.VTS constitutes only $5 \%$ of cryptorchidism cases as per literature. ${ }^{l}$ Histopathologically it is characterized by the presence of rudimentary spermatic cord with absence of normal testicular structures like seminiferous tubules. Here we report a case of one and a half year old boy who presented with a non-palpable testis in left scrotum, which was noticed by the parents a few weeks after the birth of the baby. As the left sided testes did not descend even after 1 year of age, ultrasonography was done which revealed an undescended testes in the left distal inguinal canal. After surgical exploration, we received a specimen of atrophic testis with spermatic cord. Microscopy showed fibrocollagenous tissue with congested vessels, calcification, incomplete tubular elements and hemosiderin deposition with vasdeferens in one focus. Findings were consistant with diagnostic features of a vanishing testis. Theoretically, presence of testicular tissue in a testicular remanent (eg: TRS) has got a potential for malignant transformation. Therefore most of the surgeons prefer surgical exploration of atrophic testicular remnant and subsequent histopathological confirmation.

Keywords: Vanishing testis syndrome,Testicular regression syndrome, atrophic testis,cryptorchidism.
\end{abstract}

\section{Introduction}

Vanishing testis syndrome (VTS)/Testicular regression syndrome (TRS) is a condition which is considered to be due to the subsequent atrophy and disappearance in fetal life of an initially normal testis.VTS constitute only $5 \%$ of cryptorchidism cases. ${ }^{1}$ About $3 \%$ of full term neonates show cryptorchidism at the time of birth, the prevalence of which decreases after 1 year of age. When a non-palpable testis is associated with blind ending spermatic cord, the condition is termed as Vanishing testis syndrome in urological literature and Testicular regression syndrome in Pathological literature. Histologically it is characterized by rudimentary spermatic cord with a fibrovascular tissue in the place of testicular tissue. Presence of seminiferous tubules and germ 
cells in non-palpable testis were reported in a few cases.

\section{Case Presentation}

A one and a half year boy presented to the paediatrician with his parents complaining of nonpalpable testis in left scrotum. They noticed it a few weeks after the birth of the baby during bathing and expressed their concern about it to the paediatrician. On examination, infant show normally developed external genetalia and no other external anomalies was noted. Testis was palpable in right scrotum but absent in the left scrotum/inguinal region. Suspecting an undescended testis, it was advised to wait till one year of age for the test is to descend by natural process. Left testis remained non-palpable even after 1 year of age. This time an ultrasonography was done which revealed an atrophic testicular remnant located in the left distal inguinal canal measuring about $0.9 \times 0.4 \mathrm{cms}$. A thin epididymis and spermatic cord were noted.

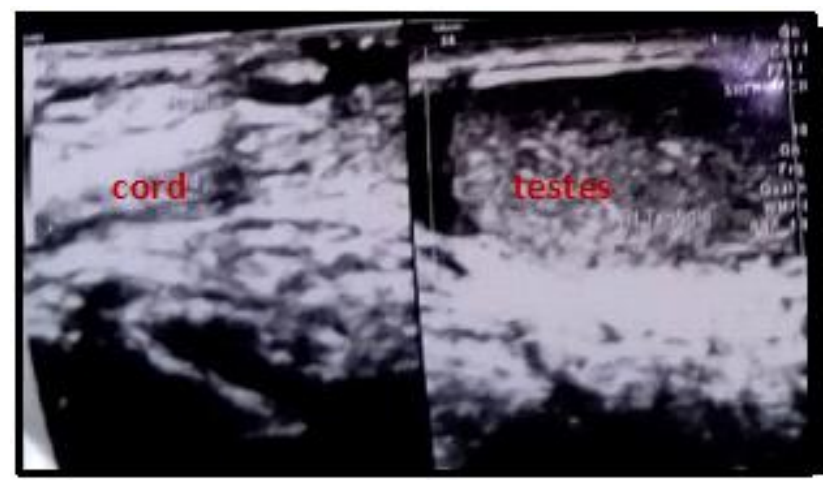

Figure (a): Right normal cord and testes

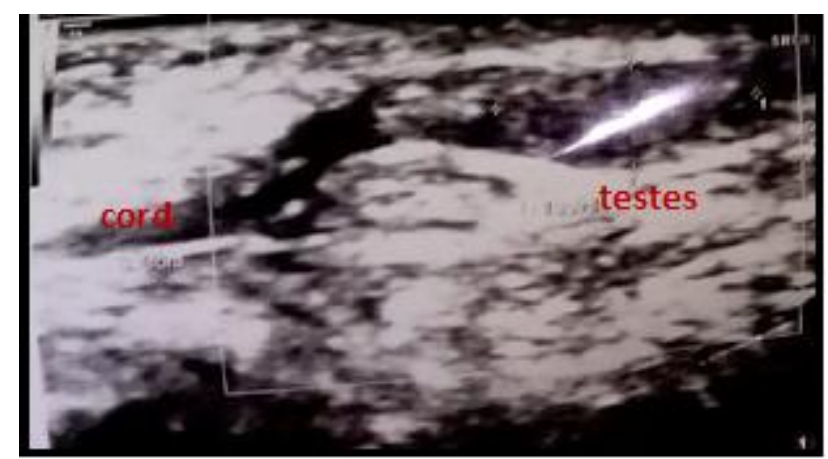

Figure (b): Left thin cord and atrophied testes
Laparoscopic exploration of left scrotum and inguinal canal was done and removal of the testicular remnant along with cord was done.

We received an atrophic testis with attached cord, measuring $1 \times 0.8 \times 0.3 \mathrm{c}$ and cord measuring $1.3 \mathrm{~cm}$ in length. Cut surface was grey white in colour.

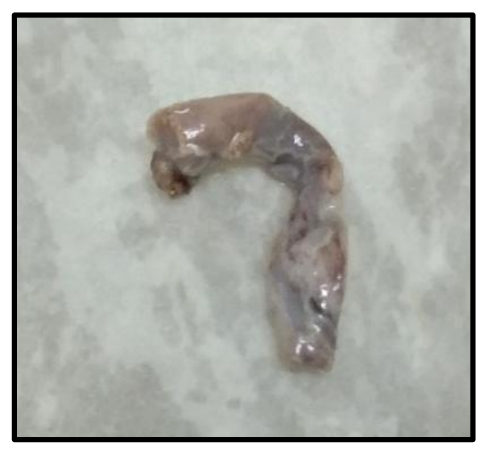

Figure (c): Gross appearance of left atrophic testes with cord

Microscopy showed portions of spermatic cord with vasdeferens and fibrocollagenous tissue with many congested blood vessels, foci of calcification, haemosiderin pigment deposits and a few seminiferous tubular remnants were noted. Periphery showed muscle tissue. There was no epididymis. No malignancy was seen. Tubules did not show Intratubular germ cell neoplasia.

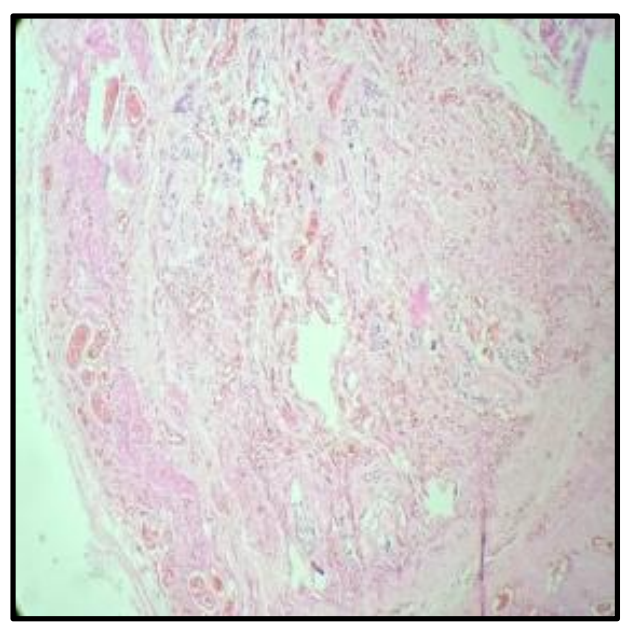

Figure (d): Fibro vascular nodule 40X (scanner view) 


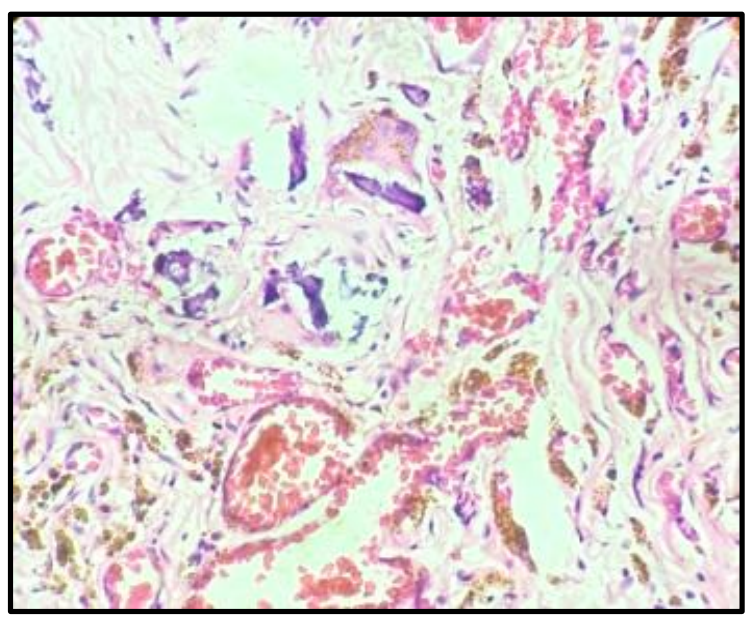

Figure (e): foci of calcification, haemosiderin deposits and a few tubular remnents (100X H\&E)

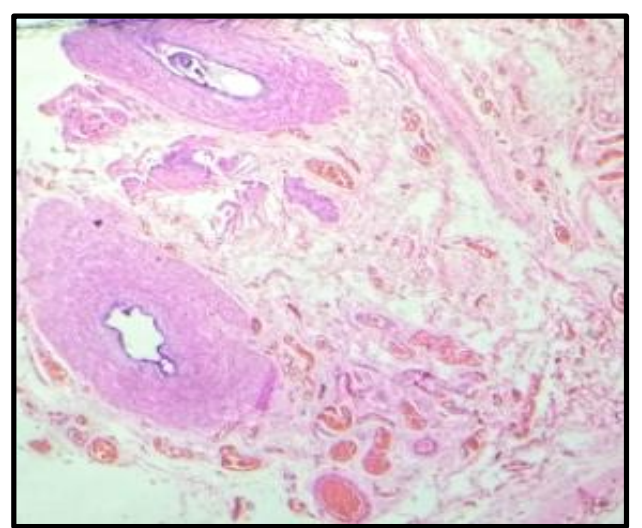

Figure (f): portion of spermatic cord with vas deferens and venous plexus (100X H\&E)

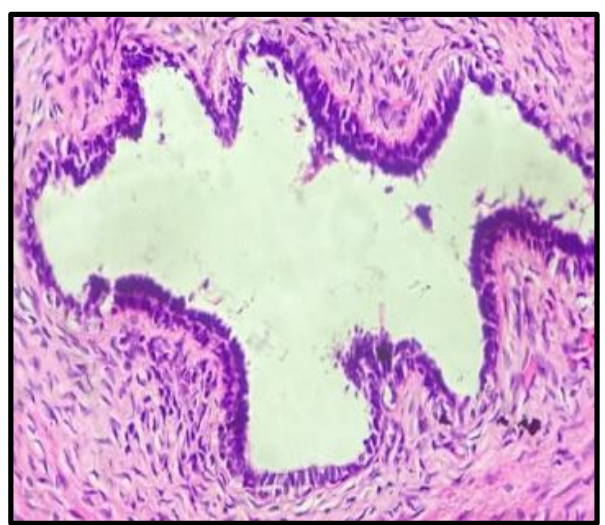

Figure (g): hypoplastic vas deferens (400X H\&E)

Final Diagnosis: Atrophic testicular tissue with vasdeferens and fibrosis, haemosiderin deposits and calcification. Consistent with Testicular Regression syndrome.

\section{Discussion}

In pathological literature, Vanishing Testis Syndrome (VTS) is often termed as Testicular Regression Syndrome (TRS).Such individuals are genetically malepresenting with unilateral/ bilateral absence of recognizable testicular structures and absence of mullerian duct system. There is a spectrum of syndromes characterized as TRS, the exact categorization depends on which stage of fetal or neonatal life the testicular function has stopped. Vanishing testis is associated with late fetal or early neonatal regression of testis. Clinically a unilateral nonpalpable testes may be associated with TRS, cryptorchidism, retractile testis or testicular agenesis. Vanishing testis is more common than testicular agenesis in patients with non-palpable testis. About $1 / 5^{\text {th }}$ of male children who present with cryptorchidism at the age of 1 year or more are found to have a non-palpable gonad. ${ }^{1,2}$

There is a lack of familiarity present among pathologists regarding Testicular Regression syndrome. According to the literature, the diagnostic criteria for pathological diagnosis of VTS/TRS include 1) a vascularised fibrous nodule with calcification and/ or hemosiderin 2) a minimum of avascularised fibrous nodule with cord elements in proximity. Vascularised fibrotic tissue replacing the testes referred to in surgical literature as "Fibrous nubbin" or "Atrophic testes" This is the most frequent finding universally present inTRS. ${ }^{2,3}$

The theory of an ischaemic event in early or late foetal stage in the form of intrauterine torsion or intravascular thrombosis leading to testicular infarction is the most accepted etiological factor. Dystrophic calcification, hemosiderin deposits and giant cells explains this hypothesis. Presence of spermatic cord structure is the evidence that the testes is formed in the early intrauterine life and is not a testicular agenesis. Microenviromental and endocrinological factors have also been proposed as the aetiology. ${ }^{4}$

Laparoscopy is a very useful tool in the localization and assessment of non-palpable testis 
and is also effective in exploring scrotum and inguinal canal for management of TRS. Presence of testicular tissue in the testicular remnant has got a long term potential for malignant transformation theoretically. Based on these some authors prefer to remove the atrophic testes to prevent malignancy, but others did not accept this due to lack of testicular tissues (germ cells) in most of the testicular remnants. ${ }^{5}$

It is preferable to look for precursors lesion of germ cell neoplasm, Intratubular germ cell neoplasia (ITGCN) in the tubular remnants in atrophic testis specimens by utilizing immunohistochemistry. ${ }^{6}$

\section{Conclusion}

Testicular regression syndrome (TRS)/Vanishing testes syndrome is a common urologic and paediatric surgical problem that is usually unrecognized by many pathologists while reporting a case of atrophic testes. There is a controversy regarding the removal of atrophic testes among the surgeons. However, when a testicular remnant is submitted for pathological evaluation, it is ideal to include the possibility of TRS in the pathological report instead of just commenting as atrophic testes with no evidence of testicular tissue.

\section{References}

1. Susan E. Spires et al, Testicular regression Syndrome: A clinical and pathological study of 11 cases; Archives of Pathology and Laboratory medicine, May 2000, Vol 124.

2. A Desai, R Verma, M Parab. A case of Testicular Regression Syndrome. The Internet Journal of surgery.2008.volume 21 number 2.

3. John. R Goldblum, Laura W. Lamps et al; Rossi and Ackerman's Surgical Pathology Textbook, volume $2,11^{\text {th }}$ edition, pages 1136-1137.
4. Christiana de Freitas Vinhas et al; Testicular Regression syndrome: a case report, Autopsy and Case reports 2012;2 (4):65-68

5. Priya Dhandore et al, Vanishing Testes Syndrome: Report of two cases, Journal of Clinical and diagnostic Research 2014, Aug Vol -8(8): ND03-ND04

6. Tatiana Antic, Elizabeth M. Hyjek, Jerome B. Taxy, The Vanishing Testis: A Histomorphologic and Clinical assessment. American Journal of Clinical Pathology, Vol 136,Issue 6,December 2011,Pages 872-880. 